\title{
The Incidence Rate of Cutaneous Leishmaniasis in Behbahan County of Khuzestan Province, Southwest of Iran
}

\author{
Hamid Kassiri ${ }^{1}$, Khadijeh Shemshad ${ }^{2, *}$, Samaneh Shojaee ${ }^{3}$ \\ ${ }_{1}^{1}$ Department of Medical Entomology and Vector Control, School of Health, Ahvaz Jundishapur University of Medical Sciences, Ahwaz, IR Iran \\ 2 Department of Medical Entomology, Faculty of Health, Mazandaran University of Medical Sciences. Sari, Iran \\ ${ }^{3}$ Health School, Member of Student Research Committee of Ahvaz Jundishapur University of Medical Sciences, Ahvaz, IR Iran \\ ${ }^{*}$ Corresponding author: Khadijeh Shemshad, Department of Medical Entomology, Faculty of Health, Mazandaran University of Medical Sciences. Sari, Iran. Tel: +98-6113738269, Fax: \\ +98-6113738282, E-mail:Khadijehshemshad@gmail.com.
}

Received: July 01, 2012; Revised: July 22, 2012; Accepted: December 15, 2012

Keywords: Incidence Rate; Cutaneous Leishmaniasis; Behbahan County; Iran

Cutaneous leishmaniasis (CL) or Oriental sore is a main public health problem in various regions of Iran. Phlebotomine sand flies are the vectors of leishmaniasis and papatasi fever in Iran $(1,2)$. CL due to Leishmania major is still a great and increasing public health problem in many rural areas of 15 out of 31 provinces of Iran (2). The predominant species of oriental sore in Khuzestan Province is $L$. major $(3,4)$. As the epidemiological aspects of $\mathrm{CL}$ in Behbahan county has not been examined in recent years for the implementation of future control measures as in order to control the disease more effectively and organize a control program, basic information is needed to be determined.

Clinical samples were consisting of all confirmed cases that referred to all health centers of Behbahan county, from 2004 until 2008 with the symptoms of leishmaniasis and presence of amastigotes in Giemsa-stained smears. For each patient in all counties, the demographic and epidemiologic features, including patient's sex, age, clinical signs, including the number of scars and its location in the body, month of diseases occurrence, incidence rate, and geographical regions were recorded by interviewing patients. Data were analyzed by using SPSS version 11.0.1.

A total number of 172 positive cases of CL were reported in the county, during 2004-2008, of which 95 (55.2\%) were male, while females accounted for 77 (44.8\%). Out of 172 positive cases of CL, 81 patients (47.1\%) resided in urban areas, while 91 (52.9\%) lived in rural areas. Analysis of the ulcers distribution in the body showed that most of the lesions, including 32\% cases were observed on hands, $31.4 \%$ cases on feet, $19.2 \%$ on face and $17.4 \%$ cases were observed on other parts of the body. Majority of the patients had only one ulcer ( $\mathrm{n}=84,48.8 \%), 34(19.8 \%), 26(15.1 \%), 28$ (16.3\%) cases exhibited two ulcers, three and more than three ulcers on their body, respectively. Highest disease prevalence $(n=39)$ was observed in February. The highest disease prevalence was in winter, so that 88 of the disease cases had occurred in this season. The most frequent cases of CL were observed significantly in the age group of 20-29 years old (27.3\%) and the least prevalence was observed in the age group of 40-49 years old. The year of 2006 had the most prevalent cases of CL (with 43 cases) in the county. The incidence of the disease in Behbahan county, during 2004-2008 were 0.12, 0.17, 0.22, 0.7 and 0.20 , respectively.

In this study, there was a relationship between gender and the incidence of disease and disease were seen more in men in comparison to women. The reason was that more men work or sleep in open areas and also due to men's less covering than women and more exposure to the infected sand flies. The most anatomical sites for lesions concentration were on the hands. Repartition of CL positive cases according to age was also in agreement with previous findings $(5,6)$, that's in general CL affect more cases in 20-29 years old adult.

Other studies have shown that most highly infected age group with $\mathrm{CL}$ is person of $\leq 20$ years old $(7,8)$. The reason for this fact is that adults have developed resistance to CL due to their previous exposure to the parasite. The age-group of 20-29 years old included patients who mostly spend their time on farms and orchards at night without self-protection $(9,10)$. The prevalence of CL had remarkable changes in the different months of year, and the highest rate was observed in February. In the present study, the highest prevalence was in winter. The reason

Implication for health policy/practice/research/medical education:

The role of cultural and demographic factors well has been described in prevalence of Cutaneous Leishmaniasis (CL) that is very important in the control of CL in Behbahan County and Iran. The study area has an important strategic position, bordering with Iraq country too.

Copyright (C) 2013, Ahvaz Jundishapur University of Medical Sciences; Licensee Kowsar Ltd. This is an Open Access article distributed under the terms of the Creative Commons Attribution License (http://creativecommons.org/licenses/by/3.0), which permits unrestricted use, distribution, and reproduction in any medium, provided the original work is properly cited. 
of this fact was related to the activity of the sand flies. Results of this study showed that most ulcers (32\%) were in hands which were similar to the results of other studies (11-13). In most cases, these parts of the body are unprotected and because sand flies are not capable of sucking the blood through clothes due to having short mouth appendices and mostly attack open and unprotected parts of the body $(10,14)$.

Results showed that $48.8 \%$ of the cases had only one ulcer on their bodies. The reason of this was because in one biting sand flies complete their feeding $(10,14)$. With regard to the findings of this study, it could be concluded that $C L$ is posed as a health problem in Behbahan county. Regarding the results of several studies from different parts of Iran, molecular study on cutaneous leishmaniasis lesions in this county is necessary $(15,16)$. Therefore, planning for the disease control and taking appropriate measures to reduce the incidence of the disease are necessary.

\section{Acknowledgements}

Authors wish to express their sincere thanks to all staffs of the Health Centers of Behbahan County and Chancellor for Research Affairs of Ahvaz Jundishapur University of Medical Sciences.

\section{Authors' Contribution:}

Hamid Kassiri developed the original idea and the protocol, abstracted and analyzed data. Hamid Kassiri and Khadijeh Shemshad wrote the manuscript. Samaneh Shojaee contributed to the development of the protocol and abstracted the data.

\section{Financial Disclosure:}

The authors have no financial interests related to the material of the manuscript.

\section{Funding/Support:}

This study was supported in part by Research Affairs of Ahvaz Jundishapur University of Medical Sciences, Ahvaz, Iran.

\section{References}

1. Talari SA, Talaei R, Shajari G, Vakili Z, Taghaviardakani A. Childhood cutaneous leishmaniasis: report of 117 cases from Iran. Korean J Parasitol. 2006;44(4):355-60.

2. Yaghoobi-Ershadi MR, Akhavan AA, Zahraei-Ramazani AR, Jalali-
Zand AR, Piazak N. Bionomics of Phlebotomus papatasi (Diptera: Psychodidae) in an endemic focus of zoonotic cutaneous leish maniasis in central Iran. JVector Ecol. 2005;30(1):115-8.

3. Ghasemian M, Maraghi S, Samarbafzadeh AR, Jelowdar A, Kalantari M. The PCR-based detection and identification of the parasites causing human cutaneous leishmaniasis in the Iranian city of Ahvaz. Ann Trop Med Parasitol. 2011;105(3):209-15.

4. Maraghi S, Zadeh A Samarbaf, Sarlak AA, Ghasemian M, Vazirianzadeh B. Identification of Cutaneous Leishmaniasis Agents by Nested Po-lymerase Chain Reaction (Nested-PCR) in Shush City, Khuzestan Province, Iran. Iran J Parasitol. 2007;2(3).

5. Aytekin S, Ertem M, Yagdiran O, Aytekin N. Clinico-epidemiologic study of cutaneous leishmaniasis in Diyarbakir Turkey. Dermato Online J. 2006;12(3):14.

6. Fazaeli A, Fouladi B, Sharifi I. Emergence of cutaneous leishmaniasis in a border area at south-east of Iran: an epidemiological survey. J Vector Borne Dis. 2009;46(1):36-42.

7. Khatami A, Firooz A, Gorouhi F, Dowlati Y. Treatment of acute Old World cutaneous leishmaniasis: a systematic review of the randomized controlled trials. J Am Acad Dermatol. 2007;57(2):335 e1-29.

8. Sharma NL, Mahajan VK, Kanga A, Sood A, Katoch VM, Mauricio I, et al. Localized cutaneous leishmaniasis due to Leishmania donovani and Leishmania tropica: preliminary findings of the study of 161 new cases from a new endemic focus in himachal pradesh, India. Am J Trop Med Hyg. 2005;72(6):819-24.

9. Kassiri H, Javadian E, Abdigoudarzi M. Natural Leishmania Infection in Meriones hurrianae and Tatera indica (Rodentia: Cricetidae: Gerbillinae) in Sistan-Baluchistan Province, South-Eastern of Iran. Adv Stud Biol. 2011;3(6):247-256.

10. Killick-Kendrick R. The biology and control of Phlebotominae sand flies. Med Vet Entomol. 1999;17:279-89.

11. Akhavan AA, Yaghoobi-Ershadi MR, Hasibi F, Jafari R, Abdoli $\mathrm{H}$, Arandian $\mathrm{MH}$, editors.Epidemiological survey in a new focus of zoonotic cutaneous leishmaniasis in Southern Iran. Glasgow Scotland. 2006;

12. Azni Sadegh, nbspMohamadi, Rassi Yavar, Oshaghi Mohamad Ali, Ershdi Mohamad Reza Yaghoobi, Mohebali Mehdi, et al. Fauna and monthly activity of sand flies at zoonotic cutaneous leishmanianisis focus in Damghan district, Semnan province (2008). Koomesh. 2010;11(2):Pe107-Pe112.

13. Razmjou S, Hejazy H, Motazedian MH, Baghaei M, Emamy M, Kalantary M. A new focus of zoonotic cutaneous leishmaniasis in Shiraz, Iran. Trans R Soc Trop Med Hyg. 2009;103(7):727-30.

14. Killick-Kendrick R. Phlebotomine vectors of the leishmaniases: a review. Med Vet Entomol. 1990;4(1):1-24

15. Mahmoodi Mohammad Reza, Mohajery Masoud, Tavakkol Af shari Jalil, Taghae Shakeri Mohhamad, Yazdan Panah Mohhamad Javad, Berenji Fariba, et al. Molecular identification of Leishmania species causing cutaneous leishmaniasis in Mashhad, Iran Jundishapur J Microbiol. 2011;3(4):195-200.

16. Saki J, Khademvatan S. A molecular study on cutaneous leishmaniasis lesions in Khuzestan province (South west of Iran). Jundishapur J Microbiol.1970;4(4)

Please cite this paper as: Kassiri $\mathrm{H}$, Shemshad K, Shojaee $\mathrm{S}$. The Incidence Rate of Cutaneous Leishmaniasis in Behbahan County of Khuzestan Province, Southwest of Iran. Jundishapur J Microbiol. 2013; 6(5):e7045. DOI: 10.5812/jjm.7045 